Coroner for the faithful discharge of the duties of his office, and holds his office at the pleasure of the Coroner.

"When any person shall come to a sudden or untimely death, and when any person shall be found dead, the manner of whose death is not known, any one who shall become aware of such death shall forthwith report the same to the Medical Examiner of the town in which the dead body lies," who shall immediately proceed to view and take charge of the dead body.

If, upon examination and inquiry, the Medical Examiner is satisfied " that the death was not caused by the criminal act, omission, or carelessness of another or others, and that there are no suspicious circumstances attending the same," he shall give a certificate of death in the usual form to the Registrar of Vital Statistics. He shall also mail or deliver to the Coroner of the county a certificate that an inquest is unnecessary.

If, on the other hand, the Medical Examiner is suspicious that any one is criminally responsible for the death, "he shall as speedily as possible, by telegraph, telephone, or otherwise, notify the Coroner for the county of such death, and of the place where the dead body is lying. Whenever the Coroner has such notice, he shall at once, and on other notice may, proceed to view and take charge of the dead body, and make all proper inquiry respecting the cause and manner of the death." If he concludes that no one is criminally responsible, he shall return a certificate of death to the Registrar of Vital Statistics. If, on the contrary, he has reason to suspect such responsibility on the part of any one, "he may cause an examinatiou or autopsy to be made of the body by the Medical Examiner, or by some other competent surgeon or physician," who shall render a written account of everything which is likely to throw any light upon the identity of the body, or upon the time, manner, and cause of death. "Should the Coroner deem it necessary, he may by warrant cause a jury of six judicious men of his county to be summoned before him, to assist him in his investigation." These men the Coroner shall instruct in their duties, and as to all points of law that may arise at the inquest. He also "may order any inquest or any part thereof to be held in private, in which case only the persons by him designated shall be allowed to remain in the room or place where such inquest is being held." If the verdict in any inquest charges any one with having caused the death which is the subject of the inquest, the Coroner shall at once communicate the import of the verdict to the prosecuting officer of the towi or city in which the death occurred. He shall within ten days return to the clerk of the Superior court the testimony of the witnesses, his own report, and the certificates sent him by the Medical Examiners. He shall, in addition, keep a complete record of all certificates made by the examiners, of all investigations made by himself, and of all testimony given before, and verdicts rendered by, juries of inquest.

Extensive powers are granted to the Coroner in regard to the summoning of witnesses and causing ar- rests in order that no means may be neglected of detecting those who are criminally responsible for unnatural deaths. In cases where wounds and injuries are received for which others are responsible, if death threatens, the Curoner shall take the statement of the person concerning the manner in which and the person by whom the injuries were inflicted If, in any case, it appears necessary to the Coroner to have a chemical or microscopical analysis, or other scientific investigation, for the purpose of ascertaining the cause of the death of the person on whose body he is holding an inquest, he shall so report to the State's attorney of his county, who may order such analysis or investigation to be made.

The medical examiners receive ten cents a mile for travel, five dollars for an external examination and twenty dollars for an autopsy. The Coroner receivcs fifteen dollars a day when necessarily employed, and forty cents a page for making the necessary records and copies. These fees are paid from the State Treasury, the bills therefor having first received the endorsement of the State's attorney.

The most striking feature of the new system is the marked tendency toward centralization. This is made apparent in the first place by the withdrawal of the authority of holding inquests from the numerous local officers elected by the voters of each town, and the placing of it in the hands of a few (eight) men who are appointed by the judges of the State. The fact that the appointments are made upon the recommendation of the State's attorneys, thus making the whole system, directly subordinate to the prosecuting office of the county, points in the same direction. Another striking feature of the system is the exceedingly insignificent position occupied by the Medical Examiner as contrasted with the unusual range of action granted to the Coroner. While the latter officer can be removed by the judge "for cause shown," the Examiners, on the other hand, hold office " at the pleasure of the Coroner,' - a strangely uncertain tenure of office. Even where an Examiner has undertaken an investigation the Coroner may at any moment interrupt the inquiry and take entire charge of it himself. If the Examiner finds reason to suspect criminality the Coroner still has the privilege, if he sees fit, of returning a certificate of death from natural causes, as if he were more competent than a physician to determine the cause of death in a doubtful case. Not even is the making of an autopsy ensured, as a definite prerogative, to the lawfully appo nted Medical Examiner, but here again the Coroner may supersede him by calling upon some one else to do it.

The law went into practical operation about the first of July. Time will undoubtedly show its defects, and, if it has any, its advantages.

\section{THE COSTATOME IN EXCISION OF THE RIB.}

$$
\text { J. F. BALDWIN, M.D., COLUmbus, OHIO. }
$$

Being called upon recently to excise a portion of a rib, in a critical case of chronic empyema in which closure of the pus cavity, which I had previously freely opened, was prevented by inability of the chest 

different methods in vogue for the performance of this operation.

The incision through the flesh is of course easy; nor is the peeling off of the periosteum difficult, but it is not so easy to cut through the bone and at the same time not injure the soft parts. The chain saw, the Hey saw and the trephine are the means usually employed to cut the bone, the soft parts being held aside meantime by retractors or by a strip of leather, pasteboard or flexible metal passed behind the rib. None of these methods, however, are free from objections, chief among which are the time required, the difficulty of protecting the soft parts, and the necessary presence of more or less bone dust in the wound. The ordinary bone forceps or cutting pliers, is better, but its points are objectionally sharp, while its shape is such that the blade cannot be easily passed between the ribs, especially when they are closely approximated as in the retracted thorax of chronic discharging empyema. I therefore hit upon the costatome as being entirely efficient, and at the same time free

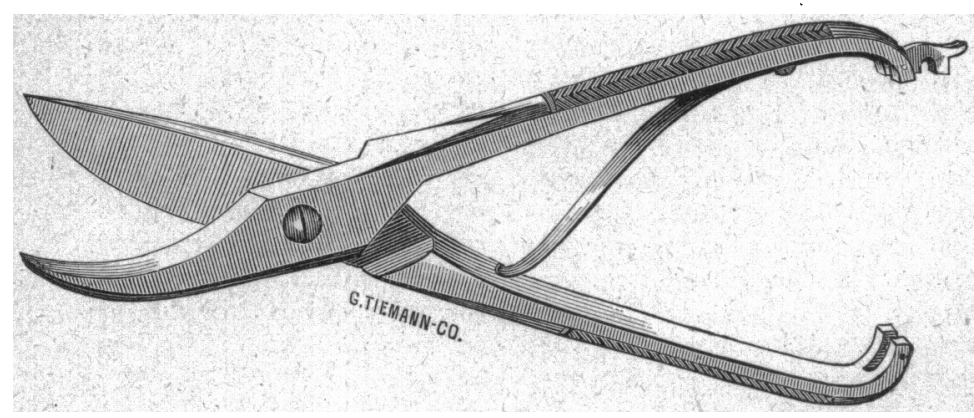

wall to further retract, I took occasion to review the from all obiections. The costatome, a cut of which

\section{MEDICAL PROGRESS.}

Poisoning by Caustic Alkali-Feeding by RecTUM FOR 49 DAYS. - Dr. McDougall, in charge of the Kulangzu Hospital, Amoy, furnishes the Customs Gazette with the notes of a case of attempted suicide in a woman, by swallowing an ounce of caustic alkali. Vomiting ensued almost immediately, the vomited matter containing a good deal of blood. Three days later the patient was admitted into the hospital very weak and pale, eyes sunken, and lips, tongue, palate, and uvula covered with sloughs. Deglutition being impossible, she was given frequent nutrient enemata, amounting in the day to fifty or sixty ounces of beef tea, eggs and milk. The enemata were retained for three or four hours. After the mouth and throat got well the patient made frequent attempts at deglutition, but without success. On the $45^{\text {th }}$ day a small sized bougie (after many unsuccessful efforts) was passed through one stricture at about the level of the thyroid cartilage, but after passing six inches beyond this point it stopped, and subsequent attempts at getting it lower proved fruitless. On the $49^{\text {th }}$ day the patient for the first time swallowed a little congee (?) and milk; this was followed by great pain in the stomach. The quantity was increased every day, until a week later she swallowed a large tumblerful of beef tea and the same quantity of milk. The rectal injections were continued. Her master took her away the next day, and four weeks later came the news of her death. It is most probable that the cestation of nourishing enemata, and the absence of appears herewith, is furnished with the more complete post-mortem cases, and is designed for opening the thorax.

The operation alluded to was performed July 26 , I 883, with the assistance of Dr. N. R. Coleman, of this city, and Dr. S. L. McCurdy, of Dennison, Ohio. The usual incision was made and the periosteum peeled off ; the blunt lower jaw of the costatome was then forced in below the rib and then up behind it, when the jaws were closed, and all present were surprised at the ease with which the bone was severed. The jaws of the instrument were again opened and pushed along the rib to the other extremity of the incision, when on closing them the operation was completed.

Owing to the spongy structure of the bone with its diploe, and to the peculiar cutting angle of the instrument, the rib is severed with much greater ease than is the phalanx in amputation of a finger with the bone pliers.

I may add, in passing, that the patient, although greatly reduced by five months of suppuration, rallied promptly after the operation; in six weeks the cavity was entirely closed, and at present the patient is, apparently, as sound and well as ever. any sufficient food that she could swallow, simply brought on death by starvation. She lived for 49 days without swallowing the smallest quantity of food, either fluid or solid, and derived so much nourishment from the enemata that she actually gained in weight.

Notes on an Epidemic Disease Observed at Pakhol.-Dr. J. H. Lowry, in the Customs Gazette, gives a general consideration of the history of bubonic plague, as given by various authors, and as preliminary to his clinical notes of ten cases of an epidemic disease, which he considers as being closely allied to the bubonic plague. The population of Pakhoi, where his cases occurred, is set down at 25,000 . The mortality was between 400 and 500 during three months, i. e.. from the end of March to the end of June, I 882. He describes the hygienic condition of the town as exceptionally bad, the streets in an abominable condition of filth, not the slightest attempt at cleanliness; the privies open, and placed, for convenience, in the most frequented parts; every house damp and foul, and the floors excrement-sodden. He gives the symptoms of his ten cases, out of which two recovered, in the following order: I. High fever. 2. Glandular swellings or buboes, varying in size from a large betel nut to a hen's egg; seldom more than one present; hard and painful; do not suppurate; 